\title{
Treatment Compliance and Radiation Associated Toxicities in Old Versus Young Patients: Prospective Comparative Case-Control Study
}

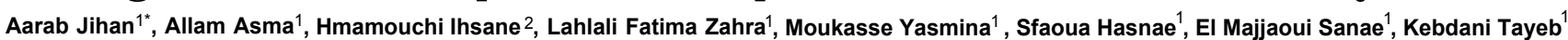
El kacemi Hanan and Benjaafar Noureddine ${ }^{1}$

${ }^{1}$ Department of Radiotherapy, National Institute of Oncology, Mohammed V University in Rabat, School of Medicine and Pharmacy in Rabat, Morocco

${ }^{2}$ Laboratory of Epidemiology and Clinical Research, School of Medicine and Pharmacy of Rabat, Mohammed V University in Rabat, Morocco

"Corresponding author: Aarab Jihan, Department of Radiotherapy, National Institute of Oncology, Mohammed V University in Rabat, school of Medicine and Pharmacy in Rabat, Morocco, E-mail: jiji199@hotmail.com

Received date: July 13, 2018; Accepted date: August 28, 2018; Published date: September 06, 2018

Copyright: $@ 2018$ Jihan A, et al. This is an open-access article distributed under the terms of the Creative Commons Attribution License, which permits unrestricted use, distribution, and reproduction in any medium, provided the original author and source are credited.

\begin{abstract}
Background: There are only few data on treatment compliance and radiation associated toxicities that occurred in old patients with cancer undergoing radiation therapy. The aim is to learn more about treatment compliance and adverse events that occurred during radiotherapy in elderly subjects compared to young subjects.

Methods: Our work is a prospective case-control study, conducted between January and November 2016. Included patients underwent radiation therapy with curative intent for various malignant tumours. 242 Patients were separated into 2 groups, according to age (cut-off 65 years). Patients and tumours characteristics were examined as well as treatment specificities. The two groups were compared in terms of treatment related toxicities and treatment compliance. Radiation associated toxicities were assessed weekly during the radiotherapy.

Results: The age distribution of the group "old patients" and "young patients" was $72.4 \pm 5$ and $48.4 \pm 8.6$ respectively. There was no significant difference in terms of toxicities according to the age group. For old patients, maximal acute toxicity was grade $3-4$ in 20 patients $(17 \%)$ and for young patients maximal acute toxicity was grade 3-4 in 26 patients $(21 \%)$. For treatment compliance, a statistically significant difference was found between old and young patients. For old patients, the scheduled RT course was completed by 96 patients $(81.3 \%)$ In the other group, RT course was completed by 116 patients $(93.5 \%)$. For old patients living place, dose of radiotherapy and toxicity grade were associated with good compliance and for young patient only sex was associated with good compliance.

Conclusion: Age alone should not be considered independently. Living condition as well as the prescribed dose should be assessed and incorporated into treatment plans.
\end{abstract}

Keywords: Radiation therapy; Treatment toxicity; Curative cancer; Chemotherapy; Conformal dosimetry; Mutltivariate analysis; Univariate analysis

\section{Abbreviations: AJCC: American Joint Committee on Cancer;} PS: Performance Status; ECOG: Eastern Cooperative Oncology Group; SD: Standard Deviation; CCI: Charlson Comorbidity Index; CTCAVE v 3.0 criteria: Common Terminology Criteria for Adverse Events Version 3.0; IQR: Interquartile Range; NCCN: National Comprehensive Cancer Network; RT: Radation Therapy

\section{Introduction}

The aging of the population is a global phenomenon. The population over sixty is growing rapidly, reflecting improving health and socio-economic conditions, but it also brings particular health challenges [1].

In Morocco, the elderly will represent $15.4 \%$ of the total population by 2030 and $23.2 \%$ by 2050 , which is twice the current rate according to the population projections of the High Commissioner for Planning
[2]. Since most tumors are age dependent, healthcare of this vulnerable population will be of a great challenge.

In fact, medical care requires in addition to treatment delivery, several aspects of social support for this category of patients including transportation, home caregiving to achieve timely help in case of serious complications during treatment, as well as psychological support, so that old patients can obtain full course regimens and optimal benefits from therapy [3].

In old patients, radiation therapy (RT) stands among treatments of first intent in curative cancer therapy [4]. Few available data from the literature indicate that RT can be highly effective and well tolerated, so that age alone should not be a limiting factor in old patients with cancer $[5,6]$.

Recommendations for or against RT should be established by a comprehensive, personalized risk-benefit assessment that evaluates the expected treatment efficacy and toxicity. Which means that an optimal risk-benefit ratio guaranties a maximal treatment efficacy (as determined by locoregional control, survival, and cancer-related symptom management) and simultaneously minimal treatment toxicity [7]. 
Page 2 of 7

Clinicians should be aware of both the potential to over treat elderly patients with significant competing non cancer mortality risk as well as the potential to under treat patients. Under treatment can result either from underestimating the patient's real life expectancy or from underestimating the aggressiveness of the cancer [8]. Because of old patients are generally excluded from trials [9-11], there are few data on the effects and toxicity of radiotherapy in this age group so there is a clear need to address the particular aspects of this specific patients group.

The aim of our work is to learn more about the treatment compliance and adverse events that could occur during radiotherapy with curative intent in elderly patients compared to young ones.

\section{Materials and Methods}

\section{Study design}

It is a single center prospective case-control study, conducted between January and November 2016. European Organization for Research and Treatment of Cancer considers 65 year old as a cutoff for the definition of old patients. In our study patients were separated into 2 groups:

Case group A: Patients aged over 65 years, who have been diagnosed with cancer, admitted in our department to receive curative treatment by RT with or without concomitant chemotherapy. RT may be exclusive, neoadjuvant or adjuvant to chemotherapy or to surgery.

Control group B: Patients aged between 18 and 65 years, who received curative $\mathrm{RT}$ in the same period.

\section{Patients and treatment characteristics}

We examined patients characteristics including age, gender, living condition (family or alone), co morbidity and medication (number of drugs $<3$ or $\geq 3$ ), tumour stage according to AJCC cancer staging [12], performance status (PS) as defined by the Eastern Cooperative Oncology Group (ECOG) [13] (0=optimum performance status, $4=$ worst performance status) [13]

patients with an ECOG score of 0 to1 were categorized as having good performance status, and those with a score of 2 to 4 were categorized as having moderate to poor performance status.

We also examined irradiated sites (head and neack, trunk or abdominopelvic), total dose, treatment duration, the use of concomitant chemotherapy (yes or no), treatment toxicity and treatment compliance.

Several comorbidity indexes are used in geriatrics, in our study we used Charlson Comorbidity index (CCI) [14].

In clinical practice, the CCI reduces comorbidities into a single numeric score that enable health professionals stratify patients into subgroups based on disease severity.

The CCI has moderate to good inter-rater reliability of 0.74 to 0.945 in older cohorts with cancer $[15,16]$. Each old patient in our sample was scored according to CCI.

\section{The following treatment characteristics were also examined}

For all patients we watched the occurrence of acute toxicity and treatment adherence (completed, interrupted stopped course). Patients who had complete scheduled RT without interruption were categorized as having good compliance, and those who interrupted or stopped treatment were categorized as having moderate to poor compliance.

Toxicity was assessed weekly during the RT course using CTCAE v3.0 criteria (Common Terminology Criteria for Adverse Events) [17] by the same physician.

Patients with grade 2 acute toxicity or less were scored as low grade toxicity, the other patients who developed grade 3 or 4 acute toxicity were scored as high grade toxicity.

\section{Statistical Analysis}

A sub-categorization of "younger old" (65-75 years), "older old" (75-85 years) and "the oldest old" ( $\geq 85$ years) has been introduced to allow allocation of elderly patients with cancer [18].

The statistical analysis was performed in three steps. Firstly, descriptive statistics were calculated for baseline characteristics primary for all patients and secondary for each group of patient's group, "old patients" group and "young patients" group defined according to the recommendations described above.

For variables that were normally distributed, the mean \pm SD was reported. For dichotomous variables, the number (\%) of patients was listed relatively to the total number of patients for whom information about the characteristics under investigation were available.

Then, we performed univariate and multivariate analysis for the whole series and for each group. We carried out several analyses between the different groups of patients.

Categorical variables were analyzed using t-Student test and chisquare or Fisher's test as appropriate and the odds ratios with $95 \%$ confidence intervals were calculated.

Factors found to be significant $(\mathrm{p}<0.20)$ in univariate analysis were included to the multivariate model. These analyses were performed using SPSS 13.0. P-Values $<0.05$ were regarded as significant.

\section{Results}

\section{Characteristics of cases and controls}

From January to September 2016, 242 patients receiving curative RT for various primary malignant tumours were identified. Group A and group B included 118 cases and 124 controls respectively.

For the whole sample the general health status was conserved with a performance status at the initiation of RT of $0-1$ in $96.7 \%(n=234)$ according to ECOG. $95.9 \%$ of the patients were living with family. Table 1 shows patient characteristics at the time of RT course.

\begin{tabular}{|l|l|l|l|l|}
\hline & Total $\mathbf{( N = 2 4 2 ) , \mathbf { n } ( \% )}$ & Old patients $\mathbf{( N = 1 1 8 ) , ~} \mathbf{n}(\%)$ & Young patients $(\mathbf{N}=\mathbf{1 2 4}), \mathbf{n}(\%)$ & $\mathbf{p}$ value \\
\hline Age (years), mean \pm SD & $60.1 \pm 13.9$ & $72.4 \pm 5$ & $48.4 \pm 8.6$ & \\
\hline
\end{tabular}


Citation: Jihan A, Asma A, Fatima ZL, Yasmina M, Hasnae S, et al. (2018) Treatment Compliance and Radiation Associated Toxicities in Old Versus Young Patients: Prospective Comparative Case-Control Study. J Nucl Med Radiat Ther 9: 373. doi:10.4172/2155-9619.1000373

Page 3 of 7

\begin{tabular}{|c|c|c|c|c|}
\hline \multicolumn{5}{|l|}{ Gender, n (\%) } \\
\hline Male & $82(33.9 \%)$ & $48(40.7 \%)$ & $34(27.4 \%)$ & \multirow{2}{*}{0.02} \\
\hline Female & $160(66.1 \%)$ & $70(59.3 \%)$ & $90(72.6 \%)$ & \\
\hline \multicolumn{5}{|l|}{ Living condition, n (\%) } \\
\hline With family & $232(95.9 \%)$ & $110(93.2 \%)$ & $122(98.4 \%)$ & \multirow{2}{*}{0.04} \\
\hline Alone & $10(4.1 \%)$ & $8(6.8 \%)$ & $2(1.6 \%)$ & \\
\hline \multicolumn{5}{|l|}{ Number of drugs, $n(\%)$} \\
\hline$<3$ & $224(92.6 \%)$ & $102(86.4 \%)$ & $122(98.4 \%)$ & \multirow{2}{*}{$<0.001$} \\
\hline$\geq 3$ & $18(7.4 \%)$ & $16(13.6 \%)$ & $2(1.6 \%)$ & \\
\hline \multicolumn{5}{|l|}{ Performance status, $\mathbf{n}(\%)$} \\
\hline ECOG $(0$ or 1$)$ & $96.7 \%(n=234)$ & $94.9 \%(n=112)$ & $122(98.4 \%)$ & \multirow{2}{*}{0.13} \\
\hline ECOG $(\geq 2)$ & $3.3 \%(n=8)$ & $5.1 \%(n=6)$ & $2(1.6 \%)$ & \\
\hline Tumor site, $\mathbf{n}(\%)$ & & & & 0.11 \\
\hline Head and neck cancer & $56(23.1 \%)$ & $26(22 \%)$ & $30(24.2 \%)$ & \\
\hline Nasopharyngeal cancer & $36(14.8 \%)$ & $14(11.8 \%)$ & $22(17.7 \%)$ & \\
\hline Laryngeal cancer & $12(5 \%)$ & $6(5.1 \%)$ & $6(4.8 \%)$ & \\
\hline Other & $8(3.3 \%)$ & $6(5.1 \%)$ & $2(1.6 \%)$ & \\
\hline Trunk cancer & $100(41.3 \%)$ & $46(39 \%)$ & $54(43.5 \%)$ & \\
\hline Breast cancer & $62(25.6 \%)$ & $26(22 \%)$ & $36(29 \%)$ & \\
\hline Lung cancer & $32(13.2 \%)$ & $16(13.6 \%)$ & $16(12.9 \%)$ & \\
\hline Oesophagus cancer & $6(2.5 \%)$ & $4(3.4 \%)$ & $2(1.6 \%)$ & \\
\hline Digestive cancer & $14(5.8 \%)$ & $10(8.5 \%)$ & $4(3.2 \%)$ & \\
\hline Gastric cancer & $8(3.3 \%)$ & $6(5.1 \%)$ & $2(1.6 \%)$ & \\
\hline Gynecological cancer & $62(25.6 \%)$ & $28(23.7 \%)$ & $34(27.4 \%)$ & \\
\hline Cervical cancer & $60(24.8 \%)$ & $28(23.7 \%)$ & $32(25.8 \%)$ & \\
\hline Endometrial cancer & $2(0.8 \%)$ & $0(0 \%)$ & $2(1.6 \%))$ & \\
\hline Urological cancer & $10(4.2 \%)$ & $8(6.8 \%)$ & $2(1.6 \%)$ & \\
\hline Prostate cancer & $6(2.5 \%)$ & $6(5.1 \%)$ & $0(0 \%)$ & \\
\hline Balader cancer & $4(1.7 \%)$ & $2(1.7 \%)$ & $2(1.6 \%)$ & \\
\hline Stage of cancer, $\mathbf{n}(\%)$ & & & & 0.27 \\
\hline Stage I or II & $90(37.2 \%)$ & $48(40.6 \%)$ & $42(33.9 \%)$ & \\
\hline Stage III or IV & $152(62.8 \%)$ & $70(59.4 \%)$ & $82(66.1 \%)$ & \\
\hline
\end{tabular}

Table 1: Patients and tumors characteristics at the time of radiotherapy course.

"Younger old" (65-74 years) cases represented $62.7 \%(\mathrm{n}=74)$ while "older old" (75-84 years) represented $37.3 \%(n=44)$. For the younger old, performance status was $0-1$ and $2-3$ in $91.9 \%$ and $8.1 \%$ respectively and the mean of CCI was $1(\max 3)$.
For the "older old" the mean of CCI was $4(\max 7)$ and they had all a performance status of $0-1$. We didn't find a significant difference in term of toxicity and compliance between the two groups "younger old" and "older old" ( $\mathrm{p}=0.9$ and $\mathrm{p}=0.07$ respectively). All treatments were 
Citation: Jihan A, Asma A, Fatima ZL, Yasmina M, Hasnae S, et al. (2018) Treatment Compliance and Radiation Associated Toxicities in Old Versus Young Patients: Prospective Comparative Case-Control Study. J Nucl Med Radiat Ther 9: 373. doi:10.4172/2155-9619.1000373

Page 4 of 7

delivered using high mega voltage linear accelerators and conformal dosimetry.
Median total prescribed dose was $60.3 \pm 1.5$ Gy using classical fractionation ( 2 Gy/day) a single fraction daily for the two groups. Table 2 shows treatment related characteristics.

\begin{tabular}{|l|l|l|l|l|}
\hline & Total (N=242) & Old patients (N=118) & Young patients (N=124) & p value \\
\hline Irradiated sites, $\mathrm{n}(\%)$ & - & - & - & 0.4 \\
\hline Head and neck & $56(23.1 \%)$ & $26(22 \%)$ & $30(24.2 \%)$ \\
\hline Chest & $100(41.3 \%)$ & $46(39 \%)$ & $54(43.5 \%)$ & $40(32.2 \%)$ \\
\hline Abdominopelvic sites & $86(35.5 \%)$ & $46(39 \%)$ & $61 \pm 14$ & - \\
\hline Total dose (Gray), mean \pm SD & $60.3 \pm 15$ & $59 \pm 16$ & $52(41.9 \%)$ & 0.28 \\
\hline Total dose, $\mathrm{n}(\%)$ & - & - & $72(58.1 \%)$ & 0.11 \\
\hline$\geq 70$ Gray & $90(37.2 \%)$ & $38(32.2 \%)$ & $49(29-58)$ & \\
\hline$<70$ Gray & $152(62.8 \%)$ & $80(67.8 \%)$ & - & 0.16 \\
\hline Treatment duration (days), median \pm IQR & $49(30-58)$ & $47(34-60)$ & - & $88(69.4 \%)$ \\
\hline Concomitant chemotherapy, $\mathrm{n}(\%)$ & - & $78(66.1 \%)$ & $36(30.6 \%)$ & 0.58 \\
\hline Yes & $164(67.8 \%)$ & $40(33.9 \%)$ & \\
\hline No & $78(32.2 \%)$ & & \\
\hline
\end{tabular}

Table 2: Treatment related characteristics.

\section{Therapeutic Compliance and Toxicity}

For the group old patients, there was no acute toxicity in 10 patients (8.5\%). 88 patients $(74.5 \%)$ had grade $1-2$ acute toxicity while 20 patients (17\%) had grade 3-4 toxicity. In the other hand, the maximal acute toxicity for group young patients was graded $1-2$ in 80 patients
(64.5\%), 3-4 in 26 patients (21\%) and there was no acute toxicity in 18 patients (14.5\%). We have detailed the toxicities observed in the two age groups in Table 3. There was no significant difference in terms of toxicities between the age groups.

\begin{tabular}{|l|l|l|l|}
\hline Acute toxicity & All patients $(\mathbf{n}=\mathbf{2 4 2})$ & Old patients $(\mathbf{n}=\mathbf{1 1 8})$ & Young patients $(\mathbf{n}=\mathbf{1 2 4})$ \\
\hline Grade $0, \mathrm{n}(\%)$ & $28(11.6 \%)$ & $10(8.5 \%)$ & $18(14.5 \%)$ \\
\hline Grade 1 to $2, \mathrm{n}(\%)$ & $168(69.4 \%)$ & $88(74.5 \%)$ & $80(64.5 \%)$ \\
\hline Grade $\geq 3, \mathrm{n}(\%)$ & $46(19 \%)$ & $20(17 \%)$ & $26(21 \%)$ \\
\hline
\end{tabular}

Table 3: Maximal acute toxicity scored with CTCAE v3.0.

For treatment compliance, a statistically significant difference was found between old and young patients $(\mathrm{p}=0.004)$. For the group old patients, the scheduled RT course was completed by 96 patients $(81.3 \%)$.

Fourteen patients $(11.9 \%)$ definitively stopped treatment and eight patients $(6.8 \%)$ temporarily interrupted RT course. The interruption lasted from 1 to 7 days.
In the other group, RT course was completed by 116 patients (93.5\%). Four patients (3.2\%) definitively stopped treatment and four patients $(3.2 \%)$ temporarily interrupted RT. The interruption lasted from 1 to 3 days. Table 4 shows compliance of treatment related characteristics.

\begin{tabular}{|l|l|l|l|l|}
\hline Compliance of treatment & All patients $(\mathbf{n}=\mathbf{2 4 2})$ & Old patients $(\mathbf{n}=\mathbf{1 1 8})$ & Young patients $(\mathbf{n}=\mathbf{1 2 4})$ & $\mathbf{p}$ value \\
\hline Good compliance, $\mathrm{n}(\%)$ & $212(87.6 \%)$ & $96(81.3 \%)$ & $116(93.6 \%)$ & 0.004 \\
\hline Moderate to poor compliance, $\mathrm{n}(\%)$ & $30(12.4 \%)$ & $22(18.7 \%)$ & $8(6.4 \%)$ \\
\hline
\end{tabular}

Table 4: Treatment compliance related characteristics. 
Citation: Jihan A, Asma A, Fatima ZL, Yasmina M, Hasnae S, et al. (2018) Treatment Compliance and Radiation Associated Toxicities in Old Versus Young Patients: Prospective Comparative Case-Control Study. J Nucl Med Radiat Ther 9: 373. doi:10.4172/2155-9619.1000373

Page 5 of 7

\section{Factors Influencing Treatment Compliance for All Patients}

In univariate analysis, gender, living conditions, performance status, number of drugs, disease stage, total delivered dose, concomitant chemotherapy and toxicity grade were associated to compliance of treatment.

In multivariate analysis, factors associated with good compliance of treatment were: Age $<65$ years $(\mathrm{OR}=0.2$, CI95\% [0.05-0.79], $\mathrm{p}=0.02)$, male patients $(\mathrm{OR}=13, \mathrm{CI} 95 \%$ [2.6-72.1], $\mathrm{p}=0.001)$, not living with family ( $\mathrm{OR}=17, \mathrm{CI} 95 \%$ [3-98], $\mathrm{p}<0.001)$, performance status $\geq 2$ $(\mathrm{OR}=113, \mathrm{CI} 95 \%$ [5.9-2163], $\mathrm{p}=0.001)$, number of drugs $\geq 3(\mathrm{OR}=8$, CI95\% [1.14-62.3], $\mathrm{p}=0.036)$, radiotherapy dose $\geq 70$ Gy $(\mathrm{OR}=0.13$, CI95\% [0.03-0.58], $\mathrm{p}=0.007)$, toxicity grade $\geq 3(\mathrm{OR}=25$, CI95\% [5.2123], $\mathrm{p}<0.001)$. Results are displayed in Table 5.

\begin{tabular}{|c|c|c|c|c|c|c|}
\hline & \multicolumn{3}{|c|}{ Univariate analysis } & \multicolumn{3}{|c|}{ Multivariate analysis } \\
\hline & OR & p & $\mathrm{Cl}$ & OR & $p$ & Cl \\
\hline Age (young) & 0.3 & 0.006 & $0.12-0.7$ & 0.2 & 0.02 & $0.05-0.79$ \\
\hline Living in institution (yes) & 5.2 & 0.014 & $1.3-19.9$ & 17 & 0.001 & 3-98 \\
\hline Gender (male) & 3.4 & 0.002 & $1.5-7.6$ & 13 & 0.001 & $2.6-72.1$ \\
\hline Performance status $(\geq 2)$ & 2.6 & 0.0001 & $5-1.37$ & 113 & 0.001 & $5.9-21.63$ \\
\hline Number of drugs $(\geq 3)$ & 2.1 & 0.19 & $0.66-7.1$ & 8 & 0.03 & $1.14-62.3$ \\
\hline Stage (III or IV ) & 2.6 & 0.043 & $1.03-6.6$ & 4,1 & 0.07 & $0.8-20$ \\
\hline Totale dose ( $\geq 70 \mathrm{~Gy}$ ) & 0.3 & 0.0001 & $0.09-0.4$ & 0,13 & 0.007 & $0.03-0.58$ \\
\hline Concomitant chemotherapy (yes) & 2 & 0.13 & $0.8-5.2$ & 1 & 0.94 & $0.21-5.2$ \\
\hline Treatment duration & 1 & 0.79 & $0.99-1$ & - & - & - \\
\hline Toxicity (grade $\geq 3$ ) & 6.9 & 0.0001 & $3-15.6$ & 25 & $<0.001$ & $5.2-123$ \\
\hline
\end{tabular}

Table 5: Factors influencing treatment compliance for all patients.

\section{Factors influencing compliance of treatment for old patients}

Male gender, living in institution, good performance status, stage of cancer, radiotherapy dose and toxicity grade were associated with good compliance.
In multivariate analysis, three factors were associated with good compliance: living in institution ( $\mathrm{OR}=7, \mathrm{CI} 95 \%$ [1.3-36.2], $\mathrm{p}=0.019)$, radiotherapy dose $\geq 70 \mathrm{~Gy}(\mathrm{OR}=0.05$, CI95\% [0.006-0.65], $\mathrm{p}=0.02)$ and toxicity grade $\geq 3(\mathrm{OR}=0.05$, CI95\% [4.05-73.7], $\mathrm{p}<0.001)$. Results are displayed in Table 6 .

\begin{tabular}{|c|c|c|c|c|c|c|}
\hline & \multicolumn{6}{|c|}{ Old Patients } \\
\hline & \multicolumn{3}{|c|}{ Univariate analysis } & \multicolumn{3}{|c|}{ Multivariate analysis } \\
\hline & OR & $\mathbf{P}$ & $\mathrm{Cl}$ & OR & $\mathbf{P}$ & $\mathrm{Cl}$ \\
\hline Living in institution & 5.1 & 0.03 & $1.16-22.3$ & 7 & 0.019 & $1.3-36.2$ \\
\hline Performance status $(\geq 2)$ & 10 & 0.009 & $1.7-61.3$ & 12 & 0.14 & $0.44-326$ \\
\hline Gender (male) & 2 & 0.14 & $0.19-1.2$ & 1.2 & 0.78 & $0.27-5.5$ \\
\hline $\mathrm{CCl}$ & 0.08 & 0.37 & $0.59-1.5$ & - & - & - \\
\hline Number of drugs $(\geq 3)$ & 1.55 & 0.48 & $0.45-5.3$ & - & - & - \\
\hline Stage disease (III or IV) & 2 & 0.16 & $0.74-5.7$ & 2.9 & 0.18 & $0.6-14$ \\
\hline Concomitant chemotherapy (yes) & 1.4 & 0.46 & $0.52-4$ & - & - & - \\
\hline Total dose ( $\geq 70$ Gy) & 0.16 & 0.02 & $0.03-0.75$ & 0.06 & 0.02 & $0.006-0.65$ \\
\hline Treatment duration (days) & 0.04 & 0.63 & $0.03-1.5$ & - & - & - \\
\hline Toxicity (grade $\geq 3$ ) & 13.2 & 0.001 & 4.3-39 & 0.05 & $<0.001$ & $4.05-73.7$ \\
\hline
\end{tabular}

Table 6: Factors influence treatment compliance for old patients. 
Citation: Jihan A, Asma A, Fatima ZL, Yasmina M, Hasnae S, et al. (2018) Treatment Compliance and Radiation Associated Toxicities in Old Versus Young Patients: Prospective Comparative Case-Control Study. J Nucl Med Radiat Ther 9: 373. doi:10.4172/2155-9619.1000373

Page 6 of 7

\section{Factors influencing treatment compliance for young patients}

In univariate analysis, factors associated with good compliance gender $\left(\mathrm{OR}=7.3, \mathrm{CI}_{95 \%}[1.2-43.4], \mathrm{p}=0.027\right)$ was associated with good compliance. Results are displayed in Table 7.

included: gender, and toxicity grade. In mutltivariate analysis, only

\begin{tabular}{|c|c|c|c|c|c|c|}
\hline & \multicolumn{6}{|c|}{ Young patients } \\
\hline & \multicolumn{3}{|c|}{ Univariate analysis } & \multicolumn{3}{|c|}{ Multivariate analysis } \\
\hline & OR & p & $\mathrm{Cl}$ & OR & p & $\mathrm{Cl}$ \\
\hline Living place (not with family) & - & 0.99 & - & - & - & - \\
\hline Performance status ( $\geq 2$ ) & 0.0001 & 0.99 & - & - & - & - \\
\hline gender (male) & 9.4 & 0.008 & $1.8-49.38$ & 7.3 & 0.027 & $1.2-43.4$ \\
\hline Number of drugs $(\geq 3$ ) & - & 0.999 & - & - & - & - \\
\hline Stage (III or IV) & - & 0.99 & - & - & - & - \\
\hline Concomitant chemotherapy (yes) & - & 0.99 & - & - & - & - \\
\hline Total dose ( $\geq 70 \mathrm{~Gy}$ ) & 0.44 & 0.32 & $0.08-2.2$ & - & - & \\
\hline Treatment duration (days) & 1 & 0.84 & $0.99-1$ & - & - & - \\
\hline Toxicity (grade $\geq 3$ ) & 4.2 & 0.05 & $0.99-18.4$ & 1.9 & 0.42 & $0.38-9.56$ \\
\hline
\end{tabular}

Table 7: Factors influencing treatment compliance for young patients.

\section{Discussion}

This is a prospective case-control study of patients treated with radiotherapy in a curative intent. We aimed to evaluate treatment compliance in different age groups of patients undergoing radiotherapy and bring out to light factors influencing treatment compliance.

Both groups, old versus young patients had the same toxicity profile unlike what was expected. Nevertheless, old patients had an increased risk to interrupt or stop treatment and that risk was associated with their residence place, gender, delivered radiotherapy dose and the toxicity grade.

A study by Wasil and colleagues has examined the issue of RT in 183 patients 80 years and older diagnosed with cancer. They found that $77 \%$ of patients were able to complete the prescribed therapy [5]. The percentage of patients who completed scheduled RT in our series is higher. This may be explained by the fact that our patients are younger (age $\geq 65$ ). Another study by Firvida and all confirms that advanced age is associated with poor treatment compliance. It also stated that performance status is a useful clinical index correlated with good compliance [19].

Living place was not significantly associated to treatment compliance in any other publication. In our study, patients living in institution had a decreased risk to interrupt or to stop treatment, which may be explained by the presence of a house caregiver. Clinicians need to provide more attention and proper counseling to these patients to maintain an effective care.
Radiation associated toxicities are known to be dose dependent and strongly correlated to irradiated normal tissue volume as well as the physiologic function of the exposed normal tissue. However, since toxicities are not consistently associated with age [20], published toxicity risks are not stratified by age. In our study we didn't find any difference of radiation associated toxicities between the two groups.

Actually, the use of advanced RT techniques like stereotactic body, volumetric RT and image-guided RT had allowed the delivery of high doses of radiation to small target volumes while limiting the risk of radiation-induced damage to normal surrounding tissues and organs at risk [6]. Concomitant chemotherapy brings higher risk of acute toxicity than single modality therapy [21]. The NCCN guidelines recommends to prescribe chemotherapy, when indicated, to elderly patients with good performance status because they can tolerate commonly used chemotherapy drugs as well as younger patients do, especially when they receive adequate supportive care [22]. Similarly, in our study, the combination of chemotherapy and radiotherapy in the elderly does not interfere with treatment compliance.

This study has several strengths and some limitations. Our study is about relatively large sample size, and it is one of the few available studies that compare treatment compliance and radiation associated toxicities between old and young patients undergoing RT with curative intent based on standardized guidelines for the assessment of toxicities.

The major limitations is that our patients didn't receive an oncogeriatric consulting before treatment start and we didn't assure a follow up after the end of RT to evaluate late toxicities. 
Citation: Jihan A, Asma A, Fatima ZL, Yasmina M, Hasnae S, et al. (2018) Treatment Compliance and Radiation Associated Toxicities in Old Versus Young Patients: Prospective Comparative Case-Control Study. J Nucl Med Radiat Ther 9: 373. doi:10.4172/2155-9619.1000373

Page 7 of 7

\section{Conclusion}

Age alone should not be considered independently. Older patients, when selected carefully, appear to tolerate well RT. Living conditions as well as the prescribed dose should be assessed and taken in consideration before treatment planning. But we still need prospective randomized controlled clinical trials of cancer treatments in old age to assure the best management for this specific patient group.

\section{Ethics Approval and Consent to Participate}

Informed consent (verbal) was obtained from all participants. This study was submitted to and approved by research and ethics committee of National Institute of Oncology.

\section{Consent for Publication}

Not applicable.

\section{Availability of Data and Materials}

The datasets used and/or analysed during the current study are available from the corresponding author on reasonable request.

\section{Competing Interests}

The authors declare that they have no competing interests.

\section{Funding}

Special thanks are due to the Faculty of Medicine and Pharmacy of Rabat; the source(s) of funding for all authors.

\section{References}

1. Yancik R, Ries LA (2004) Cancer in older persons: An international issue in an aging world. Semin Oncol 31: 128-136.

2. Haut-Commissariat au Plan du Maroc. http://www.hcp.ma/

3. Balducci L, Extermann M (2005) Management of cancer in the older person: A practical approach. Oncologist 5: 224-237.

4. Ausili-Cefaro G, Olmi P (2001) The role of radiotherapy in the management of elderly cancer patients in light of the GROG experience. Crit Rev Oncol Hematol 39: 313-337.

5. Wasil T, Lichtman SM, Gupta V, Rush S (2000) Radiation therapy in cancer patients 80 years of age and older. Am J Clin Oncol 23: 526-530.
6. Kunkler IH, Audisio R, Belkacemi Y, Betz M, Gore E, et al. (2014) Review of current best practice and priorities for research in radiation oncology for elderly patients with cancer: The international society of geriatric oncology (SIOG) task force. Ann Oncol 25: 2134-2146.

7. Smith GL, Smith BD (2014) Radiation treatment in older patients: A framework for clinical decision making. J Clin Oncol 32: 2669-2678

8. Bian SX, Hoffman KE (2013) Management of prostate cancer in elderly men. Semin Radiat Oncol 23: 198-205.

9. Lewis JH, Kilgore ML, Goldman DP, Trimble EL, Kaplan R, et al. (2003) Participation of patients 65 years of age or older in cancer clinical trials. J Clin Oncol 21: 1383-1389.

10. Yee KW, Pater JL, Pho L, Zee B, Siu LL (2003) Enrollment of older patients in cancer treatment trials in Canada: Why is age a barrier? J Clin Oncol 21: 1618-1623.

11. Jean claude Horiot (2007) Radiation therapy and the geriatric oncology patient. J Clin Oncol 25: 1930-1935.

12. AJCC cancer staging manual. (8th edition), Springer

13. Oken MM, Creech RH, Tormey DC, Horton J, Davis TE (1982) Toxicity and response criteria of the eastern cooperative oncology group. Am J Clin Oncol 5: 649-655.

14. Charlson ME, Pompei P, Ales KL, MacKenzie CR (1987) A new method of classifying prognostic comorbidity in longitudinal studies: Development and validation. J Chronic Dis 1: 373-383.

15. De Groot V, Beckerman H, Lankhorst GJ, Bouter LM (2003) How to measure comorbidity. A critical review of available methods. J Clin Epidemiol 56: 221-229.

16. William H H, Ramanathan R, Samir N, Ashesh B J, Srinivasan V (2004) An electronic application for rapidly calculating Charlson comorbidity score. BMC Cancer 4: 1471-2407.

17. National Cancer Institute, Common Terminology Criteria for Adverse Events v.3.0.(CTCAE).

18. Sheryl L, Parker MSPH, Tony T, Sherry B, Phyllis A (1996) Cancer statistics-1996. CA Cancer J Clin 47: 5-27.

19. Jose LF, Nura V, Montserrat M, Juan J, Grau, et al. (1999) Age: A critical factor in cancer management. A prospective comparative study of 400 patients. British Geriatrics Society 28: 103-105.

20. Marks LB, Ten Haken RK, Martel MK (2010) Guest editor's introduction to QUANTEC: A users guide. Int J Radiat Oncol Biol Phys 76: S1-S2.

21. Greven K, Winter K, Underhill K, Fontenesci J, Cooper J, et al. (2004) Preliminary analysis of RTOG 9708: Adjuvant postoperative radiotherapy combined with cisplatin/paclitaxel chemotherapy after surgery for patients with high risk endometrial cancer. Int J Radiat Oncol Biol Phys 59: 168-173.

22. NCCN Clinical Practice Guidelines in Oncology (2017) (NCCN Guidelines $^{\circledast}$ ) Older Adult Oncology. 